\title{
APLICACIÓN DE LAS HERRAMIENTAS DE COMUNICACIÓN A UN EVENTO TURÍSTICO: EL CASO XACOBEO
}

\author{
Magdalena Rodríguez Fernández \\ Universidad de A Coruña: Escuela de Turismo \\ mmrodriguez@udc.es
}

Material autorizado para su primera publicación en la revista académica como artículo.

https://doi.org/1017979/redma.2010.01.04.4707

\section{Magdalena Rodríguez Fernández}

Doctora en Ciencias Económicas y Empresariales por la Universidad de A Coruña; Licenciada en Ciencias Económicas y Empresariales por la Universidad de Santiago de Compostela; Postgrado en Economía y Calidad en el Sector turístico por la Universidad de A Coruña; Docente en la Escuela Universitaria de Turismo y en el Master Oficial en Dirección y Planificación del Turismo de la Universidad de A Coruña. Participación en diversos congresos nacionales e internacionales. 


\title{
RESUMEN:
}

El objetivo del presente trabajo consiste en analizar la importancia que para un destino turístico como Galicia ha supuesto la creación de un evento como es el Xacobeo. Para ello se estudian las distintas herramientas de comunicación empleadas en la promoción de los tres eventos celebrados hasta hoy: Xacobeo 93, Xacobeo 99 y Xacobeo 04, con la finalidad de determinar la repercusión de las mismas en todo el proceso de la comunicación como variable del marketing operativo, y destacar la importancia y eficacia de cara a su posterior aplicación en la celebración de nuevos eventos como en el caso del actual Xacobeo 2010.

Palabras clave: Herramientas de comunicación, Xacobeo, Galicia

\author{
ABSTRACT: \\ APPLICATION OF COMMUNICATIONS TOOLS IN A TOURISM EVENT: THE XACOBEO CASE
}

The aim of this paper is to analyse the significance of creating an event such as the Xacobeo (a programme of activities organised to commemorate a Holy Year) for Galicia as a tourist destination. It includes the study of the various communication tools that have been used to promote the three editions of this event that have been held to date - Xacobeo 93, Xacobeo 99 and Xacobeo 04 -, in order to determine their impact on each stage of the communication process as a tactical marketing variable, and on highlighting their importance and efficiency with a view to their future application to other events such as the Xacobeo 2010.

Key words: Communication tools, Xacobeo, Galicia 


\section{EL XACOBEO COMO EVENTO TURÍSTICO}

Un evento, desde una conceptuación general, se convierte en producto turístico cuando está dotado de un carácter universal, tiene interés general, cuenta con un atractivo multifacético y se erige en polo de atracción de públicos foráneos al ámbito geográfico propio en el cual se desarrolla. $\mathrm{Y}$, además, directa $\mathrm{o}$ indirectamente, ofrece los servicios adecuados para dar satisfacción a las necesidades de los destinatarios del mismo. Un producto turístico que, por su propia naturaleza y singularidad, suele tener una identidad sumamente acentuada debido a la peculiaridad de los rasgos propios y la proyección de la misma genera la percepción en los públicos de una imagen cuya debilidad o fortaleza dependerá, en gran medida, de la minoración de los efectos perniciosos del ruido a lo largo de todo el proceso de comunicación. Una imagen que, a su vez, también incidirá en la propia del entorno en el cual se lleva a cabo y en la de las entidades, públicas o privadas, promotoras o colaboradoras del mismo. Una debilidad o fortaleza que, por otra parte, dependerá también del grado de sostenibilidad del evento en el tiempo y todo ello, en conjunto, contribuirá decisivamente a la creación de un determinado posicionamiento respecto a sus competidores mediante la ocupación de un espacio en la mente de aquellos a quien va destinado.

Así, cuando el evento pasa a ser un producto turístico cabe encuadrarlo dentro de las definiciones clásicas de éste último, en orden a observar en él una combinación de elementos tangibles e intangibles que dan forma a la experiencia vivida por el turista y le generan utilidades o beneficios (Altés, 1993; Ascanio, 1991; Ashworth, 1991; Buhalis, 2000; Go, 1992; Goodall, 1990a; Heath y Wall, 1992; Middleton 1994; Valls, 1992; Rey et al., 2004; Milio Balanza, 2004). En definitiva, desde la perspectiva genérica del producto como satisfactor de necesidades transformadas en deseos de un determinado grupo de 
consumidores, el turístico no deja de constituir un conjunto de elementos susceptibles o no de tangibilidad, naturales y artificiales, que actúan de forma interrelacionada con el fin último de dar respuesta a las necesidades del turista de la manera más eficiente y satisfactoria. De ahí que, de acuerdo con Aguirre (2000), los componentes principales del producto turístico pueden enmarcarse en dos grandes grupos: los recursos (naturales, históricos, culturales y religiosos) y los servicios o equipamientos (servicios o equipamientos propiamente turísticos: hoteles, agencias de viajes, guías, etc.), y (servicios o equipamientos generales: vías de acceso, medios de transporte, etc.).

Si se tiene en cuenta el hecho de que el turismo, en términos generales y como conjunto de actividades, desde hace tiempo mantiene un sólido liderazgo en el sector servicios y en respuesta a la demanda generada en la actual sociedad del ocio (Serra, 2009), ha de apreciarse la consecuente saturación generada en la oferta de destinos turísticos y someter a éstos al pertinente análisis del ciclo de vida del producto a fin de plantear estrategias que permitan su relanzamiento mediante su adaptación a los deseos actuales de los públicos a los cuales se dirigen. $Y$ aquí, en dicha adaptación del producto turístico, a las exigencias de la demanda actual, potencial y futura, es donde ha de situarse al evento como un elemento esencial para la captación de turistas por parte de un destino determinado.

Para este trabajo el producto turístico configura el pilar básico en el cual se sustenta el evento Xacobeo. En este sentido, sin la existencia del Camino de Santiago $^{1}$ y la percepción del mismo como producto turístico, la creación del Xacobeo no hubiera alcanzado la notoriedad y posicionamiento actual y hubiese

1 Camino de Santiago o Ruta Jacobea: constituye un conjunto de rutas de peregrinación hasta el sepulcro del apóstol Santiago el Mayor en Compostela, y hace referencia a las vías, que procedentes de diferentes regiones europeas cruzan todo el continente. La diversidad en cuanto a la procedencia de los peregrinos ha favorecido su conversión en una ruta cultural de gran importancia para la configuración de Europa. 
acabado por convertirse en un evento efímero o bien casi inadvertido entre todos los ya existentes tanto a nivel nacional como internacional.

Por otra parte, ha de señalarse que la revisión de los conceptos y definiciones acerca del turismo de eventos, por ser éste el que más se relaciona con el Xacobeo, constituye una tarea compleja debido a la utilización indistinta de diferentes términos para caracterizar a esta actividad (Maure, 2007).

Sin embargo, puede constatarse que se trata de un tipo de turismo de gran importancia para una ciudad, región o país, debido a que incentiva el desarrollo socioeconómico local, al contribuir a la generación de empleos, rentas, así como a la creación de infraestructuras que benefician no sólo al turista, sino también a la población local. Además, este tipo de turismo, en ocasiones puede ser la solución óptima al problema de estacionalidad tan acusado en este sector.

Nos encontramos así, ante una actividad que moviliza gran cantidad de personas, tanto desde el punto de vista de la oferta turística como del de la demanda.

Las motivaciones de este tipo de turistas pueden ser de distintos tipos, desde profesionales, laborales, culturales, religiosas, aventureras, ecológicas, placenteras, etc.

Ahora bien, desde una perspectiva más adecuada al objeto central de este trabajo, se entiende por evento a cualquier tipo de reunión profesional de corte científico, técnico, cultural, deportivo, educativo, político, social, económico, comercial, religioso, promocional o de otra índole que facilite el intercambio de ideas, conocimientos y/o experiencias entre los participantes (Colectivo de autores, 2003). 
Se trata de un acontecimiento que puede ser celebrado con carácter de perpetuidad o no, sirve para que un destino se dé a conocer y atraiga a un número considerable de visitantes. Estos acontecimientos extraordinarios trascienden al ámbito local y generan la asistencia de público para que participen en ellos.

Durante los últimos años, la organización de grandes eventos se ha revelado como una de las principales estrategias de desarrollo de las ciudades, pues suponen un recurso económico que propicia el atractivo para el turismo e impulsa el resto de actividades de la ciudad (Elizagarate, 2003).

Una vez situados en su contexto los conceptos relativos a este tipo de turismo, es preciso destacar que los orígenes del Xacobeo como evento se remontan a 1991, año en el cual se aprueba el denominado "Plan Xacobeo 93".

Para Galicia los objetivos de este plan se fundamentaban en potenciar la imagen de la Comunidad Autónoma, percibida y vinculada por entonces al atraso y aislamiento, e impulsarla hacia la modernidad a través del turismo.

La idea era crear un evento de gran repercusión y conseguir que Galicia se posicionase como un destino de referencia en el ámbito turístico. Para lo cual se tomarían como referencia, desde el punto de vista promocional, la celebración de dos acontecimientos claves que tuvieron lugar durante el año 1992 en España y que, a su vez, habían logrado cambiar, respectivamente, la imagen de las ciudades de Barcelona y Sevilla.

La creación de este evento para Galicia debía basarse en estrategias sostenibles en el tiempo debido a la gran implicación que ello conllevaba, y no convertirse en un evento de carácter efímero. El objetivo del plan era crear un 
verdadero evento turístico, sustentado en la importancia histórica que el Camino de Santiago proyectaba a nivel nacional e internacional.

El Xacobeo por lo tanto, configura en sí mismo un concepto complejo, amplio e integrado.

Por un lado se trata de un evento que tiene lugar en los Años Santos ${ }^{2}$, también se refiere básicamente a la estrategia promocional de Galicia llevada a cabo por la Administración Autonómica, y cuyo objetivo principal consiste en la atracción de visitantes, no sólo a Santiago de Compostela sino a todo el territorio gallego (Lois y Santos, 1997).

Por otro lado, constituye una apretada agenda de actividades culturales y espectáculos.

Y por último el Xacobeo también es en sí mismo una marca comercial registrada perteneciente a la "Sociedad Anónima de Xestión do Plan Xacobeo3", que en la actualidad está suficientemente consolidada y se utiliza con asiduidad cuando es Año Santo. Esta marca integra los aspectos antes mencionados, resultando extensible a toda la Comunidad gallega, de modo que pervive siempre vinculada al Camino de Santiago y a los acontecimientos celebrados en los diferentes itinerarios de peregrinación que se dirigen a Compostela.

2 Año Santo: cuando la festividad del apóstol Santiago ( 25 de julio) coincide en domingo, de modo que la periodicidad responde a un ciclo de $6,11,6$ y 5 años.

3 S. A. de Xestión do Plan Xacobeo: empresa pública de la Xunta de Galicia creada en 1991 como medio de apoyo para la ejecución de las acciones relacionadas con el Camino de Santiago o Ruta Jacobea y los Años Jubilares y que en la actualidad depende de la Consellería de Cultura y Turismo. 
Hoy en día existe un cierto consenso de académicos, especialistas, peregrinos y visitantes ${ }^{4}$ que coinciden en destacar que el Xacobeo ha contribuido a cambiar la imagen de Santiago de Compostela y de Galicia, es decir, que ha habido un antes y un después tras la creación de este evento.

Es por lo tanto importante que se persevere en la explotación de los rasgos distintivos de los que goza el evento Xacobeo, con la finalidad de conseguir una posición en el mercado que, a su vez, represente una ventaja competitiva, lo cual otorgará a la marca un valor dirigido a acabar por repercutir positivamente en el éxito de la misma.

En todo este proceso la comunicación como se verá más adelante, ha jugado un papel trascendental a lo largo de las tres ediciones celebradas hasta hoy.

\section{IMPORTANCIA DE LA COMUNICACIÓN COMO VARIABLE DEL MARKETING OPERATIVO EN EL SECTOR TURÍSTICO}

Para que un producto, una marca o un evento turístico puedan llegar al público objetivo es necesario hacer uso de la comunicación, la cual representa el instrumento mediador entre lo que el producto, la marca o el evento transmite y como ello es percibido por el público. Aquí también se cumple la idea de Locke, radicalizada por Hume (Broackes,J., 2009; Woolhouse, R., 2009), en cuanto al conocimiento y sintetizada popularmente en la aseveración de que sencillamente "no existe aquello que no se conoce", y el conocimiento solamente se adquiere a

\footnotetext{
4 Información recogida de las entrevistas en profundidad realizadas como parte de la investigación cualitativa para la Tesis Doctoral: "Análisis de la identidad, imagen y comunicación del Xacobeo como evento y marca y su influencia en la promoción de Galicia como destino turístico", defendida, en la Universidad de A Coruña, por Magdalena Rodríguez Fernández, bajo la dirección del Dr. Valentín Alejandro Martínez Fernández.
} 
través de la experiencia y la comunicación. Pero, en este caso, no se trata tan sólo de emplear la comunicación para dar a conocer el evento sino de cómo se utiliza estratégicamente para posicionarlo en el mercado turístico y muy especialmente en la mente del público (Pérez, 2001). Esto significa que ha de tenerse especial cuidado en la elección de las estrategias y herramientas de comunicación a utilizar, pues de ello podría depender en cierta medida el éxito o el fracaso de los mismos, sobre todo en un primer momento (Massoni, S., 2007).

Por este motivo la comunicación va a jugar un importante papel como medio de canalización de información. Bello, Vázquez, y Trespalacios (1996) la definen como un proceso de transmisión de mensajes entre un emisor (empresa) y un receptor (consumidor, público objetivo), a través de un medio sometido a ruidos que distorsiona tanto los mensajes como cualquier otro elemento del proceso.

La comunicación convencional es además una de las variables relevantes del marketing mix de los productos y destinos turísticos. $\mathrm{Y}$ entendida conceptualmente como el proceso a través del cual un emisor transmite cierta información sobre sí mismo o sobre sus productos (mensaje) a sus públicos de interés y a la sociedad en general. Su objetivo esencial consiste en influir en el comportamiento de dichos públicos y lograr una actitud favorable hacia la organización o su oferta al tiempo de establecer los mecanismos pertinentes para conocer dicha respuesta o efecto (retroalimentación).

Las estrategias de comunicación implican decisiones relativas al uso de los instrumentos del mix de comunicación o promocional de los que dispone la organización, así como la determinación de la población objetivo, mensajes y medios que se han de emplear (Royo, 2002).

De ahí que la utilización conjunta de los elementos de comunicación dependerá de las características del destino o producto turístico, población objetivo a la que 
se dirige, objetivos de la campaña de comunicación y la estrategia utilizada por los destinos o productos competidores (Bigné et al., 2000).

Las características del producto, el precio y los canales de distribución, son elementos comerciales relevantes; sin embargo, para lograr que los consumidores adquieran una determinada marca, casi siempre se necesita la ayuda de la comunicación promocional (Alén, Fraiz, y Mazaira, 2007).

Esto enfatiza que una comunicación precisa, coordinada y adecuada de un destino, producto, marca o evento turístico es fundamental para generar experiencias susceptibles de identificarse con la idea de calidad que tenga el público destinatario de la misma (Zeithmal, 1998; Zeithaml y Bitner, 2000).

En este sentido, la comunicación como variable del marketing mix, desde el punto de vista turístico, integra principalmente técnicas como la publicidad (convencional y no convencional), la promoción de ventas, las relaciones públicas y la venta personal que, en la práctica, han de actuar conjunta y coordinadamente para ayudar a construir una identidad propia y mediante su proyección generar una imagen adecuada del destino y de la oferta cultural (Bigné, Font y Andreu, 2000).

Pero no sólo los canales formales de comunicación (por ejemplo los folletos), sino que también los informales (el caso de los prescriptores), influyen sensiblemente en la formación de la imagen de un destino turístico por parte de los públicos a los cuales se dirigen las acciones de comunicación (Goodall, 1990b).

El objetivo de este trabajo es por lo tanto destacar la importancia que presenta la variable comunicación del marketing operativo. Pero como las herramientas que integran la comunicación de los productos y eventos turísticos son muy 
variadas, aquí se matizan principalmente las que más se identifican con nuestros objetivos y que se agrupan por un lado en: la publicidad, la comunicación por acción, las relaciones públicas, la promoción de ventas, el marketing directo, y las ferias y exposiciones.

Por otro lado, el merchandising, el producto emplazado o product placement y los prescriptores van a desempeñar también un papel relevante en el ámbito de esta investigación.

\section{LAS HERRAMIENTAS DE COMUNICACIÓN Y EL XACOBEO}

\subsection{LA PUBLICIDAD}

La publicidad para Martín Armario (1980) consiste en una técnica o instrumento a disposición del responsable comercial para que, con hábil manejo de la misma pueda influir sobre la cifra de ventas, incrementándola.

Los objetivos de la publicidad son por lo tanto: informar acerca de la existencia de un producto, marca o evento; persuadir al consumidor creando o modificando sus actitudes hacia la marca mediante el uso de mensajes racionales o emocionales; reforzar el comportamiento de compra pasado o actual; y recordar la existencia de un producto o marca.

Para la Sociedad Anónima de Xestión do Plan Xacobeo, empresa gestora del evento, la publicidad directa no ha constituido una herramienta prioritaria en la promoción del Xacobeo, y pasa así a ocupar un segundo plano, en detrimento a otros instrumentos promocionales (Xunta de Galicia, 1994).

Las acciones, en este sentido, buscaban atraer y acercar a la diversidad de públicos hacia Galicia en general y a Santiago de Compostela en particular, para 
que allí pudiesen disfrutar y participar de las actividades que se celebraban con motivo de la conmemoración de los Años Santos. Para ello se utilizaban distintas herramientas publicitarias como: vallas y lonas; anuncios en prensa y televisión acerca de los distintos actos y acontecimientos del Xacobeo; videos promocionales en pantallas interiores de los autobuses urbanos, y cortinillas en las emisiones de la Televisión de Galicia en sus cortes publicitarios.

\subsection{LA COMUNICACIÓN POR ACCIÓN: PATROCINIO Y MECENAZGO}

Para Rodríguez del Bosque (1997) tanto el patrocinio como el mecenazgo son técnicas de comunicación por acción, que permiten asociar y promover una imagen y prestigio de marca o de la empresa, para lo cual se utiliza un acontecimiento atractivo para un público objetivo determinado (Bello, Vázquez y Trespalacios, 1996).

Así el patrocinio puede definirse como una relación comercial entre un suministrador de fondos, de recursos o de servicios, y una persona, un acontecimiento o una organización, que ofrece a cambio algunos derechos y una asociación que puede utilizarse para conseguir una ventaja comercial a la que se llega a través de una actividad de ocio o estilo de vida por un camino indirecto, aparentemente menos comercial (Sleight, 1992).

Y el mecenazgo como un aporte de recursos económicos o en especie para financiar la realización de un proyecto, sin más razones que el sentido altruista, la propia satisfacción personal y la creencia en los valores de la causa, no existiendo, por tanto, intenciones ocultas o comerciales (Martínez Fernández et al. (2004) citando a Díez de Castro et al., (2002)).

Hoy en día, ante la creciente saturación de los medios convencionales la comunicación por acción va ganando terreno, aprovechando fundamentalmente 
las ventajas que aporta tanto para la imagen de la organización, como los incentivos de tipo fiscal que animan su práctica (Martínez, 2004).

Al hablar de comunicación por acción en el caso Xacobeo hay que destacar que tanto el patrocinio como el mecenazgo configuran las principales herramientas promocionales empleadas para la difusión del evento.

Por lo que respecta al Xacobeo, en su figura de patrocinador, cabe subrayar la importancia dada al deporte, en sus diferentes modalidades, toda vez que su presencia en el ámbito deportivo, ha constituido un medio idóneo para la promoción de este acontecimiento en los últimos años.

La relación se inicia ya en el año 1992 con el patrocinio de la vuelta ciclista a España y como antesala al Año Santo de 1993. Gracias al amplio seguimiento que los medios de comunicación desarrollaron durante esos años, se logró que Galicia, Xacobeo y el Camino de Santiago empezasen a sonar a nivel nacional e internacional. Pero esta modalidad de deporte no sería la única, el fútbol también fue objeto de patrocinio en los años 98-99 y 2004, la instalación de vallas publicitarias en todos los campos de fútbol de primera división, contribuyeron a familiarizar a millones de personas con la nueva imagen del Xacobeo diseñada entonces para el año 1999 y 2004.

La vela y las actividades náuticas en general también suscitarían el interés del Xacobeo, al ayudar a promocionar el turismo náutico en Galicia. Del mismo modo, el patrocinio del golf en el año 1999, constituyó una gran oportunidad para dar a conocer a todo el mundo las condiciones óptimas en las que se encontraban las instalaciones gallegas para la práctica de este tipo de deporte.

Una práctica deportiva, igualmente habitual a lo largo de todos los Xacobeos han sido las actividades relacionadas con el mundo del motor. 
Otras disciplinas que del mismo modo han contado con el patrocinio del Xacobeo a lo largo de sus tres últimas ediciones, son el baloncesto, el atletismo, el tenis, el voleibol, la hípica o las regatas de globos aerostáticos, entre otros.

Pero no sólo el Xacobeo, desempeñó el rol de patrocinador, también ha sido objeto de patrocinio por parte de empresas privadas, lo cual ha contribuido a garantizar el éxito en muchas de la actividades programadas a lo largo de los últimos Años Santos. El apoyo que muchas empresas mostraron al Xacobeo, permitieron sufragar económicamente la organización de múltiples exposiciones, conciertos, congresos y actividades deportivas, y difundir la marca identificativa del Xacobeo en sus propias campañas publicitarias.

Desde el año 1993, el número de empresas patrocinadoras del Xacobeo ha ido incrementando de forma considerable a raíz de la celebración de cada nuevo Año Santo. Esto pone de manifiesto el interés, la repercusión y la buena acogida que experimenta el Xacobeo en cada nueva edición, así como la importancia cada vez mayor que muestran las empresas privadas por colaborar con el evento y beneficiarse de la imagen positiva que éste proyecta.

Han sido muchos los sectores implicados en el patrocinio, sin embargo las compañías de transporte y las agencias de viaje son quienes se llevan la palma.

A lo largo de las tres ediciones sólo dos empresas han estado siempre presentes como patrocinadoras: Iberia y El Corte Inglés. Ésta última instaló además, en todos sus centros comerciales repartidos por toda España, expositores con material informativo acerca del Camino de Santiago y las actividades relacionadas con el Xacobeo. 
Pero además de todas las empresas patrocinadoras que han apoyado al Xacobeo a lo largo de los años, hay que destacar la importancia que también han tenido los convenios de colaboración firmados por la Xunta de Galicia con otras empresas y que del mismo modo han contribuido a desarrollar las actividades del evento. Entre dichas empresas se encontraban: Fadesa, Fríos, Mondariz, Pescanova y La Caixa.

Por lo que respecta al mecenazgo como herramienta promocional, las actividades parecen ser más reducidas, hay que destacar en este caso la colaboración económica de la S.A. para la promoción y gestión del Xacobeo en los trabajos de restauración de la fachada de la catedral de Santiago.

En este aspecto el proyecto de conservación y restauración del Pórtico de la Gloria y su entorno, de las pinturas murales de la Capilla Mayor, así como la ordenación de los Museos Catedralicios forma parte del "Programa Catedral de Santiago de Compostela", puesto en marcha por la Fundación Pedro Barrié de la Maza como acciones de mecenazgo. Incorpora también un programa de visitas donde se puede observar cara a cara las figuras que diseñó el Maestro Mateo.

Otra iniciativa de interés es la desarrollada por la organización Médicos del Mundo en Galicia con la finalidad de captar fondos para apoyar los programas del Cuarto Mundo, bajo el lema "Xacobeo Solidario".

\subsection{LAS RELACIONES PÚBLICAS}

Las relaciones públicas deben entenderse como un conjunto de acciones de comunicación orientadas a crear vínculos de relación permanente con los públicos afectados por la actividad de una empresa, institución o evento (Bigné, 2003). 
Las relaciones públicas externas apoyan su labor en técnicas muy variadas, con especial relevancia de la publicity ${ }^{5}$, la celebración de visitas guiadas o recepción de grupos de visitantes, la convocatoria de premios, la organización de congresos, jornadas y seminarios, las visitas guiadas de tipo institucional, etc. (Reinares, 1999).

Esta herramienta de comunicación también ha protagonizado un papel muy importante a lo largo de las tres ediciones del evento. Ha permitido crear y consolidar la imagen de Galicia y del Xacobeo como un referente tanto a nivel nacional como internacional.

Durante el año 1993, entre las acciones de relaciones públicas más utilizadas cabía destacar, la organización de congresos y encuentros científicos, con el objetivo de fomentar la investigación y los estudios jacobeos y de este modo lograr atraer a Galicia a especialistas prestigiosos en distintas áreas, y contribuir así a promocionar el turismo de congresos.

Las convocatorias de certámenes, también supusieron una forma de promocionar el evento. La finalidad en este caso, era premiar las ideas creadoras de profesionales, aficionados y de escolares, en diversas áreas: teatro, poesía, periodismo, fotografía, vídeo, pintura, escultura y música.

El Xacobeo 99 colaboró y favoreció del mismo modo, en la organización de cursos, reuniones y encuentros dirigidos al intercambio de estudios, análisis e ideas de diversa índole: historia, cultura, etc. Los congresos relacionados con la tradición jacobea y el fenómeno de la peregrinación a Compostela fueron de nuevo los protagonistas a lo largo de este año.

5 Publicity: estimulación impersonal de la demanda de un producto, servicio o idea por medio de noticias comercialmente relevantes difundidas por los medios de comunicación de masas y no pagadas directamente por el anunciante. Entre los medios que emplea esta técnica destaca los comunicados o notas de prensa, las conferencias de prensa y la generación de noticias, American Marketing Association (AMA). 
Por un lado, la colaboración llevada a cabo entre la Xunta de Galicia, la Universidad y otras instituciones y entidades españolas, se materializaría en unos 270 congresos, reuniones, simposios y seminarios realizados a lo largo de 1999 por toda Galicia.

Por otro lado, los encuentros multitudinarios entre jóvenes (Ruta QuetzalArgentaria y la Peregrinación y Encuentro Europeo de Jóvenes) habían servido para difundir lo que Galicia estaba viviendo durante los Años Santos, lo que permitió de este modo, que Santiago fuera el lugar elegido por numerosos colectivos, colegios profesionales, federaciones y asociaciones nacionales e internacionales para celebrar sus congresos.

Durante el año 2004, se celebraron también más de 100 congresos en distintos puntos de Galicia y Portugal. A lo largo de todo el año, las siete ciudades gallegas fueron escenario de una intensa actividad congresual, cuya temática principal sería el Camino de Santiago y el Xacobeo. Los acuerdos firmados con las universidades gallegas para la celebración de congresos y seminarios durante este año, también serían importantes como medio de difusión y promoción del evento. Al igual que había ocurrido en el Xacobeo 99, en 2004, se organizarían de nuevo los encuentros de la juventud.

También, la colaboración de la Xunta con otras instituciones españolas fue decisiva para la difusión del evento, se fomentarían así relaciones con otras comunidades y regiones españolas por las que transcurre el Camino de Santiago. De estos acuerdos surgiría la celebración en el año 1993 y 1999 de los Días Institucionales del Xacobeo, dedicado a las distintas Comunidades Autónomas. 
En 2004, a la celebración de estos Días Institucionales de Comunidades y ciudades españolas, se añadiría la de los días dedicados a países como el día de Chile y el de Suiza. Pero Santiago ya había contado anteriormente con la presencia de autoridades políticas de otros países dentro del marco de la celebración del Xacobeo, como habían sido las visitas de los presidentes de Bolivia o del primer ministro portugués en 1993, lo que favorecería su conversión en embajadores del evento en sus respectivos países.

Y por último habría que destacar el apoyo importante mostrado por diferentes instituciones en la promoción del Xacobeo a lo largo de los últimos años, entre ellas se encontrarían: la Real Casa de Moneda y Timbre, el organismo de Loterías y Apuestas del Estado, el Ejército, el Instituto Mapfre de Seguridad Vial, el Colegio Oficial de Arquitectos o la Asociación de Empresarios de Hostelería de Santiago.

Pero no se puede hablar de relaciones públicas, sin hacer mención a la importancia que el papel de la publicity como herramienta de comunicación, ha tenido a lo largo de las tres ediciones.

En realidad han sido muchos los medios de comunicación, tanto nacionales como extranjeros, que a lo largo de estos años han dirigido su atención hacia Galicia y al Xacobeo, incluyendo de este modo noticias y reportajes de temática jacobea en revistas, radio y televisión. Todas estas acciones, habían contribuido a la difusión de actividades culturales y festivas enmarcadas en la programación de la celebración del Año Santo, y a reforzar la formación de la imagen del Xacobeo en todos los sectores de la sociedad.

Así el Xacobeo y el Camino de Santiago fueron noticia casi a diario y objeto de numerosos especiales en las publicaciones más variadas, hasta el punto, de que la presencia de Galicia en los medios de comunicación de fuera de nuestras 
fronteras se incrementó en un 1.400 por ciento durante los Años Santos (Xunta de Galicia, 1994).

A lo largo de estos años, muchos medios de comunicación también se hacían eco a diario de la agenda de actividades del Xacobeo, especialmente en el caso de los grandes eventos deportivos y conciertos.

Los grandes acontecimientos del Xacobeo como la apertura de la Puerta Santa (que marca el inicio del Año Santo Compostelano), o la celebración del Día de Galicia el 25 de julio (donde la mayoría de las grandes cadenas de radio y televisión españolas suelen realizar sus programas informativos desde la capital gallega), eran objeto de un gran despliegue informativo. La concesión del premio Príncipe de Asturias de la Concordia 2004 al Camino de Santiago, fue también un hecho ampliamente recogido por los medios de comunicación en todo el mundo.

Pero las noticias relacionadas con el Xacobeo no son únicamente exclusivas de Galicia o Santiago. Todas las comunidades por las que transcurre la Ruta Jacobea habían sido, del mismo modo, objeto de continuos reportajes sobre las peregrinaciones, iniciativas locales, conferencias o estudios sobre el Camino de Santiago. Ello contribuiría aún más si cabe, a difundir y extender el Xacobeo por todo el norte peninsular, así como por otras regiones españolas y europeas por los que discurre la ruta.

Los viajes de familiarización, dirigidos principalmente a touroperadores, agentes de viajes y periodistas configuraron otro tipo de relaciones públicas muy utilizada, en el caso del Xacobeo y el Camino de Santiago. La finalidad de esta herramienta era lograr que personalmente conociesen la oferta turística y así, la pudiesen recomendar a otras personas. Además se jugaba con la ventaja de que se trata de una técnica de elevada credibilidad para el público objetivo, lo cual 
favorecería a que la gente mostrase interés por conocer lo que es el Xacobeo y todo lo que ello configura.

\subsection{LA PROMOCIÓN DE VENTAS}

La promoción de ventas es un conjunto de herramientas de incentivos a corto plazo, diseñadas para estimular rápidas y/o grandes compras de un producto particular por el consumidor o por el mercado (Kotler, 1989).

Entre las técnicas que utiliza la promoción de ventas hay que destacar: descuentos, rebajas en precios, cupones, vales, muestras, regalos, premios, concursos, sorteos, juegos, tarjetas de fidelización, city cards, ofertas sistemáticas, ofertas selectivas, etc.

En este caso la promoción de ventas sobre todo a través de ofertas, descuentos y tarjetas de fidelización constituye una herramienta de comunicación muy empleada para favorecer el bienestar y disfrute de los peregrinos que durante días recorren muchos de los kilómetros del Camino de Santiago, o bien para los visitantes de día y turistas que deciden acercarse a Santiago de Compostela ciudad y meta de la peregrinación, o a cualquier otro lugar de Galicia.

Al analizar esta herramienta se han encontrado distintas modalidades de promoción de ventas de la que se pueden beneficiar tanto los peregrinos que realizan el Camino, como los visitantes de día y turistas que se aproximan a Compostela o a Galicia, a lo largo de cualquier año, sin necesidad de que sea Xacobeo.

De este modo, cabe destacar aquí algunas de ellas: 
El Bono lacobus, que consiste en un servicio turístico diseñado específicamente para el Camino de Santiago con descuentos en determinadas casas de turismo rural para los caminantes que realicen por etapas distintas vías históricas de la Ruta Xacobea (Camino Francés, Camino de Fisterra-Muxia y Vía de la Plata). El precio de este bono incluye la cena, el alojamiento, desayuno y traslados en coche desde los establecimientos rurales hasta el inicio o final de cada etapa. Puede incluir además otros servicios opcionales si se requiere.

El circuito Pelegrín Spa en Santiago, permite al caminante gozar de descuentos y ofertas en determinados establecimientos que disponen de este tipo de servicios en la ciudad.

Galicia premiun, se trata de un programa de fidelización, diseñado por Turgalicia y que permite premiar a los viajeros que escojan con frecuencia Galicia como destino de sus viajes. Esta tarjeta, comprende promociones y servicios exclusivos para sus clientes totalmente gratuitos si se alojan en la red de alojamientos turísticos de Galicia adheridos a este programa.

Existen además otros tipos de descuentos realizados por diferentes establecimientos de alojamiento o restauración situados a lo largo de las diferentes rutas del Camino de Santiago, que realizan reducciones en sus precios a los caminantes por su condición de peregrinos.

En este sentido también merece la pena destacar el caso del Hostal de los Reyes Católicos en Santiago de Compostela, donde cada día invita a los diez primeros peregrinos que se personen en la puerta del garaje a un desayuno, comida y cena. 
Todas estas acciones de promoción de ventas pretender estimular al consumidor turístico para que disfrute de un producto, servicio o destino durante un periodo de tiempo limitado.

\subsection{EL MARKETING DIRECTO Y MARKETING ON LINE}

El marketing directo es un sistema de venta que puede ser empleado tanto por el productor del bien o servicio, como por el intermediario, que además merece una atención propia por dos razones: su desarrollo e implantación y su carácter distintivo con respecto a otras fórmulas de distribución (Rufín, 2002). Incluye herramientas como el telemarketing, el correo electrónico, el mailing/buzoneo, la venta por catálogo, los folletos, los compact dics, pen drive (como sustituto en ocasiones de la herramienta anterior) y las bases de datos.

Es importante destacar también dentro del marketing on line, como el desarrollo de las tecnologías de la información y comunicación ha sido significativo para el sector turístico y ha supuesto una importante revolución tanto en la comercialización como en la promoción de productos o destinos turísticos.

Al hablar de marketing directo aplicado al Xacobeo, hay que hacer mención a la elaboración de folletos y hojas informativas publicadas a lo largo de los años, con la finalidad de informar, promocionar y difundir las rutas de peregrinación, las actividades culturales, los acontecimientos enmarcados en la programación del Xacobeo, etc.

Se puede diferenciar por un lado entre; las publicaciones editadas directamente por la Xunta de Galicia y la S.A. de Xestión do Plan Xacobeo; y por otro lado entre; las realizadas por dichos organismos en colaboración con asociaciones, 
instituciones $u$ otras entidades con intereses en la promoción de uno o todos los itinerarios jacobeos.

Los folletos editados para el Xacobeo 93, tenían como objetivo principal, promocionar el entonces recién recuperado Camino Francés ${ }^{6}$ como itinerario jacobeo por excelencia y al mismo tiempo presentar Galicia como un destino turístico emergente a través de su condición de principio y fin del Camino de Santiago. La información que se ofrecía era de tipo generalista.

En el Xacobeo 99, se apreciaban cambios importantes, desde un nuevo logotipo, hasta la recuperación de nuevas rutas de peregrinación, por lo que se hacía necesario el diseño de nuevos folletos que incorporasen las modificaciones. La información en este caso era más detallada, y con un mejor diseño gráfico. $A$ pesar de ello, se reiteraba la poca funcionalidad que presentaban estos folletos.

Por eso en el Xacobeo 2004, los nuevos folletos abogaban por un diseño más moderno y atractivo, donde la información era más clara y detallada.

Tras la celebración de los tres Xacobeos y en la actualidad de acuerdo a la celebración del nuevo Xacobeo 2010, se siguen editando nuevos folletos y se presenta el producto Camino de Santiago y la marca Xacobeo desde la perspectiva de la modernidad y consolidación de Galicia como destino turístico.

Además de la edición de todos estos folletos y hojas informativas, hay que destacar que existen otras publicaciones donde la Xunta de Galicia ha prestado

6 Camino Francés es una de las rutas del Camino de Santiago. Se ha convertido en el camino por definición al ser el más concurrido y conocido, por ello en muchas ocasiones la denominación del Camino de Santiago alude exclusivamente a éste. Debe su nombre al elevado número de peregrinos franceses que lo elegían y también a que su recorrido fue institucionalizado en el siglo XII por el Códice Calixtino. Se inicia en los puntos más lejanos de Europa y cruza en España las Comunidades Autónomas de Aragón, Navarra, La Rioja, Castilla-León y Galicia. 
su colaboración y han servido para divulgar el Camino de Santiago como itinerario, así como las diferentes rutas de peregrinación hasta Galicia.

Pero al analizar el marketing directo en este caso, no se puede obviar la importancia de la aplicación de las nuevas tecnologías como Internet en la difusión de la marca y todo lo que ella engloba.

Hoy en día Internet ha contribuido a un rápido crecimiento de páginas web en el sector turístico. Por eso son cada vez más las páginas que aparecen con la finalidad de vender, comunicar y satisfacer a los diferentes consumidores turísticos.

Una página web, que por primera vez y durante el año 2004 había sido fundamental como soporte para la difusión de todos los programas de las comunidades autónomas relacionados con el evento Xacobeo, y que a lo largo de ese año ofrecía información era www.spain.info.

También la página web: www.xacobeo.es, constituyó y constituye un punto de información y de encuentro para muchos peregrinos y para el público en general, acerca de la multitud de acontecimientos, actividades y noticias que genera la celebración del evento.

Existen además entre otras, dos páginas web, que permiten al peregrino, visitante de día y turista disponer de toda la información necesaria acerca de: la ruta de peregrinación; la ciudad compostelana; o la Comunidad Autónoma. En www.santiagoturismo.com y www.turgalicia.es, el público objetivo puede encontrar referencias suficientes para disfrutar de su peregrinación, de una oferta completa de ocio o de una estancia agradable en el destino. 
La revolución de las comunidades o redes sociales online, se puede decir que también han llegado al fenómeno Xacobeo y en este caso, en un primer momento de la mano de un grupo de peregrinos alemanes.

En www.caminofriends.com, los interesados tras registrarse para poder configurar la cuenta y manejar todas las funcionalidades, pueden acceder en cinco idiomas (inglés, alemán, francés, italiano y español) a colgar sus fotografías, contar las impresiones sobre sus experiencias, editar sus propios diarios de viajes, consultar noticias, etc. Es por tanto una buena forma para que los peregrinos compartan sus experiencias y conozcan a personas que hayan vivido situaciones similares a lo largo de una ruta de peregrinación inolvidable como es el Camino de Santiago.

También los gestores y promotores del evento, a través del buscador Google han apostado por posicionar el Xacobeo en todas sus herramientas como: Youtube, la creación de rutas en Google Maps y Google Earth, y la presencia en las principales redes sociales como Tuenti, Twitter, y Facebook, con la finalidad de que este acontecimiento pueda llegar a todo el mundo de la mano de las nuevas tecnologías.

\subsection{EL MERCHANDISING}

Según la American Marketing Association, el merchandising se define como un conjunto de técnicas basadas principalmente en la presentación, rotación y la rentabilidad, comprendiendo un conjunto de acciones llevadas a cabo en el punto de venta destinadas a aumentar la rentabilidad, colocando el producto en el lugar, durante el tiempo, en la forma, al precio y en la cantidad más conveniente. 
Para promocionar la marca Xacobeo de forma permanente, se han llevado a cabo colaboraciones con diversas empresas. Éstas se encargaban de la fabricación de objetos que incorporaban los símbolos identificativos del Xacobeo.

Se crearon y comercializaron, por lo tanto hasta un total de veinticuatro objetos diferentes: desde camisetas, gorras, lápices, adornos de cerámica, pins, ambientadores, gemelos, prendedores de corbatas, hasta globos, pelotas, paraguas, mochilas, marca páginas, etc., que consiguieron ser lo suficientemente atractivos como para que peregrinos y turistas los comprasen y llevasen de recuerdo en su paso por Galicia. Esto posibilitó a que la marca traspasase las fronteras y empezase a sonar y alcanzar una mayor notoriedad fuera de la Comunidad.

\subsection{LAS FERIAS Y EXPOSICIONES}

Las ferias son una forma de presentación, y en ocasiones de venta, periódica y de corta duración de productos de un sector a intermediarios y prescriptores. Su principal utilidad se deriva del establecimiento del contacto personal entre distintos colectivos implicados: touroperadores, agencias minoristas, organismos públicos y otros (Bigné et al., 2000).

Una manera de conseguir que un destino, un producto, una marca o un evento lleguen a un determinado público objetivo es acudir a las ferias y exposiciones que repartidas por todo el mundo se celebran con cierta frecuencia.

Este motivo es el que ha llevado al Xacobeo, a estar presente a lo largo de sus tres ediciones en numerosas ferias y exposiciones con la finalidad de buscar su promoción desde el punto de vista turístico. 
Fuera de Galicia se optó por el diseño de exposiciones que permitiesen dar a conocer en todo el mundo la figura del apóstol Santiago y el Año Santo, así como aspectos concretos de la programación del Xacobeo y del atractivo turístico que Galicia posee.

En este sentido se había apostado por la presencia, incluso antes de la celebración del primer Xacobeo en el año 1992, en la Feria Internacional de Turismo (FITUR en Madrid), o el Pabellón de Galicia en la Expo de Sevilla, con la finalidad de que todo el mundo se fuese familiarizando con el acontecimiento que tendría lugar al año siguiente.

Desde ese momento, han sido varias las ferias nacionales e internacionales en las que el Xacobeo, el Camino de Santiago y Galicia han estado representados.

En el año 1993, caben precisar: FITUR (Madrid), Expocio (Madrid), Salón del Turismo de Cataluña (Barcelona), Expovacaciones (Bilbao), Turisport (SilledaPontevedra) y Semana Verde (Berlín).

En 1999, se vuelve a optar por las ferias y las exposiciones promocionales, destinadas tanto a colectivos profesionales del sector como al público en general como estrategias de difusión del Xacobeo. Exposiciones y muestras en Europa e Hispanoamérica lograron crear notoriedad para la marca. La participación en las ferias turísticas de Madrid, Barcelona, Bilbao o Berlín al igual que en el año 1993, así como en otras ciudades como Lisboa, Milán, París, Roma o Londres habían contribuido a la promoción del Camino de Santiago y del Xacobeo.

A lo largo del año 2004, la presencia del evento en ferias se multiplicaría, tan sólo en Galicia, se promocionaba en Turisport (Silleda), Expogalaecia (Vigo), Fimo (Ferrol), Gastronomía y turismo (Ourense), Fexdega (Vilagarcía), ForumEnsino (Ourense) y Ferpalia (Pontevedra); en el resto de España, estuvo 
presente de nuevo en FITUR, SIT (Barcelona) y Expovacaciones (Bilbao), Agroturismo (León), Turicom (Gijón) e Intur (Valladolid).

También en el ámbito internacional, el evento estuvo representado en diversas ferias turísticas como Vakantiebeurs Utrech, CMT Stuttgart, MIT Milán, Salón Mundial de París, Salón des Vacances de Bruselas, STEPS, WRM de Londres, Resiemarkt en Colonio, ABAV-Brasil, Turismo de Berlín y BTL en Lisboa.

Y por último, hay que destacar la importante participación que el Xacobeo ha tenido también en diferentes muestras multisectoriales realizadas en distintos lugares tanto de España como de Europa.

\subsection{EL PRODUCTO EMPLAZADO O PRODUCT PLACEMENT}

Este término ha sido adoptado mayoritariamente para definir una forma de comunicación que consiste en hacer aparecer el producto de la empresa, de acuerdo con una estrategia comunicacional, dentro de una serie televisiva o película cinematográfica, sin alterar su desarrollo argumental (Reinares, 1999).

En este sentido la televisión y el cine han sido y son un medio idóneo para la promoción del Xacobeo. Santiago de Compostela, así como diversos puntos de la Ruta Jacobea, han servido de decorado para documentales, programas, películas, conciertos, concursos y series de televisión.

Así en el año 1993, se promovía la primera producción de serie para televisión "Los Caminos de Santiago", donde un peregrino mostraba los secretos y maravillas al recorrer el Camino Francés desde Roncesvalles, el Camino Portugués y las Rutas del Mar de Arousa y Finisterre. Serie que se emitió en todas las cadenas de televisión autonómicas españolas y en un total de 23 
países de Europa y América gracias al canal internacional de TVE. Este hecho facilitó un mayor acercamiento al producto turístico Camino de Santiago.

La filmación de una película en formato cine "El Camino de las Estrellas", donde el espectador tenía la oportunidad de realizar un viaje a través de las fiestas, costumbres y tradiciones populares gallegas por medio de la historia de amor fantástica entre una sirena y un hombre-lobo también contribuyó a la promoción de Galicia como destino turístico.

Durante el año 1993, otro hecho destacable era el nacimiento de un programa semanal "Desde Galicia para el mundo" que todavía hoy se sigue emitiendo en España y en el canal internacional para toda Europa y América. Este programa ha desempeñado un papel crucial durante los últimos Años Santos al difundir en el exterior la agenda de acontecimientos y actividades celebrados con motivo del Xacobeo.

En 1999, fueron muchos los hechos relacionados con el mundo de la televisión y del cine los propulsores del Camino de Santiago, el Xacobeo y Galicia.

Así, un documental de la televisión brasileña inspirado en la obra de Paulo Coelho "Peregrinos a Compostela"; un capítulo completo de una serie de ficción de gran audiencia dedicado al Camino de Santiago en Antena 3; la grabación de otra serie de coproducción internacional basada en una idea original del escritor Arturo Pérez Reverte para televisión y que contaría con la presencia de actores de fama mundial como Anthony Quinn, Charlton Heston, Anne Archer o Imanol Arias; el estreno de otra película inspirada en un cuento del gallego Manuel Rivas; la creación de los personajes que acompañarían al popular Xabarín de la Televisión de Galicia en sus aventuras a lo largo del Camino por el dibujante Miguel Anxo Prado para una serie de animación íntegramente gallega; los reportajes sobre el Año Santo que la cadena norteamericana CNN emitió con 
una amplia difusión; y la retrasmisión de los principales acontecimientos deportivos y culturales organizados con motivo del Xacobeo por los canales internacionales fueron propicios para impulsar, difundir, promocionar y dar a conocer un evento de tales características.

Igualmente en 1999 se emitió por la Televisión de Galicia el documental "Os camiños do aire". En el que una pareja de peregrinos recorrían el Camino de Santiago, desde Roncesvalles y hasta Santiago de Compostela, en un globo aerostático. Un peregrinar que en Cacabelos se uniría a una regata aerostática que concluiría en la Plaza del Obradoiro. Este documental alcanzaría un record en audiencia al emitirse en prime time.

En el año 2004, las películas, los documentales, y los concursos, también jugaron un importante papel como medios para la difusión y promoción del Camino de Santiago y del Xacobeo.

Así la película "Tres en el Camino", contaba las vivencias de tres personas que procedentes de diferentes culturas decidían emprender por separado su peregrinación a Compostela.

El documental "Nuestros Caminos a Santiago" de Carmelo Gómez, para la Televisión Española, mostraba a lo largo de quince capítulos de treinta minutos de duración un recorrido por las principales rutas que conducen a Santiago.

Un concurso creado por la televisión vasca para la cadena ETB2 bajo el nombre de "La flecha amarilla", consistía en que diez concursantes divididos en grupos de cinco, lograsen realizar el Camino de Santiago, partiendo de la localidad de Doribane Garazi y superasen al mismo tiempo diferentes pruebas. 
Años más tarde y concretamente en 2007 llegaba a Galicia un concurso con un formato similar y de temática jacobea, bajo el nombre "O Gran Camiño", donde un grupo también de diez concursantes debían emprender el Camino, desde Roncesvalles hasta Santiago, superando para ello diversas pruebas y con un claro objetivo: dejar de fumar.

En agosto de 2008 se estrenaba en España una película francesa "Peregrinos" bajo el género de comedia-drama, cuya trama argumental se desarrollaba a lo largo del Camino de Santiago. A lo largo de esta historia el espectador recorre unos paisajes espléndidos, al mismo tiempo que puede asistir con los protagonistas a experimentar miedos, enfados, fantasías, amoríos, etc., que viven a lo largo del Camino.

Durante 2009 hay que destacar también la película, "Al final del Camino", protagonizada por Fernando Tejero y Malena Alterio. Se trata de una comedia que transcurre a lo largo del Camino de Santiago, se centra en dos periodistas que fingen ser pareja para hacer un reportaje sobre un gurú, quien recomienda recorrer la Ruta Jacobea como solución para las crisis conyugales.

Asimismo National Geographic Channel exploraba el Camino de Santiago en una serie documental que recuperaba el espíritu de los peregrinos medievales y realizaba el recorrido completo de la ruta Jacobea, desde Haarlem, en Holanda, hasta la Catedral de Santiago de Compostela. El resultado fue "En el Camino de Santiago", seis entregas de media hora de duración, que se estrenaron en el mes de mayo.

Y ya en la actualidad es importante mencionar el rodaje de la película "The way", por la productora Filmax. Se trata de un film que transcurre en el Camino Francés a Santiago y que está protagonizado por Martin Sheen y su hijo, Emilio Estévez, quien dirige además la cinta. 
Así el producto emplazado como herramienta de comunicación ha sido aplicada al Camino de Santiago tras diversas creaciones para televisión sobre todo durante los Años Xacobeos, convirtiendo de este modo, el itinerario en escenario de las tramas argumentales, y aprovechando así todos los efectos que se generan.

\subsection{LOS PRESCRIPTORES}

El prescriptor es un profesional ligado a una actividad económica cuyas decisiones o trabajo específicos inducen a la compra de un producto o servicio por parte del cliente (Díez de Castro et al., 2002).

Se trata por lo tanto de una persona cuyo cargo profesional o notoriedad pública puede ser empleada en beneficio de mejora de la imagen de una empresa, producto o evento a través de su vinculación directa o indirecta con el mismo.

Desde tiempos remotos han sido muchas las personalidades que han pasado por Santiago de Compostela. La iglesia, la política, la cultura y la vida social han estado representadas en la celebración de los distintos Años Santos y han supuesto un medio idóneo para la promoción del Xacobeo.

Citar a todas las personas sería un imposible, por eso se ha optado por agruparlas desde diferentes perspectivas.

Desde la Edad Media, han sido numerosos los personajes ilustres de la historia que han recorrido el Camino en peregrinación a Santiago, como búsqueda 
personal o inspiración para el ejercicio de su profesión, tales como reyes, caballeros, nobles, Papas, obispos, arzobispos y santos.

Ya en el siglo XX, las visitas del Papa Juan Pablo II a Santiago de Compostela en 1982 y 1989, fueron uno de los factores que más contribuyeron en su momento, a la eficacia de las peregrinaciones jacobeas. También la vinculación de los miembros de la Casa Real Española con el Camino de Santiago, ha sido y continua siendo muy intensa.

Pero no sólo la Casa Real Española, también la Casa Real Belga, y en su representación, la reina Fabiola se ha aproximado a visitar la tumba del apóstol Santiago en 1993 y 2004.

Por otro lado, la relación del Camino de Santiago con personalidades del mundo de la cultura, las artes, el espectáculo y el deporte también ha sido constante.

Es por tanto que en el año 1986, el escritor brasileño Paulo Coelho decide peregrinar a Compostela. Este viaje le motivaría para escribir un año después su libro "El Peregrino a Compostela" donde narra las vivencias en su peregrinación a Santiago y descubre lo extraordinario del Camino y de sus gentes. Hecho que revela la fuerza de la literatura como vehículo de promoción. A partir de ese momento el escritor regresaría de nuevo a Compostela en numerosas ocasiones.

Personajes como Andrew Bertie, gran maestre de la Orden de Malta visitó la ciudad del apóstol en 1993, en compañía de más de 150 caballeros y damas pertenecientes a la Orden.

También la actriz norteamericana Shirley Maclaine recorrería el Camino Francés en 1994. Posteriormente, recogería su experiencia acerca de la peregrinación en 
el libro "El Camino: Un viaje del espíritu". Libro que acaparó grandes ventas en EEUU y contribuyó a que muchos de los lectores manifestasen el deseo de peregrinar a Compostela una vez que lo habían leído.

Otros personajes que del mismo modo han visitado o peregrinado a Santiago de Compostela durante el Año Santo de 1999 han sido; el actor Anthony Quinn; el escritor portugués, José Saramago; el ex-secretario general del Consejo de Europa, Daniel Tarschys; Federico Mayor Zaragoza, ex-secretario general de la UNESCO; Juan Abelló, ex-presidente de la Fundación Airtel ( Vodafone en la actualidad); el actor y empresario norteamericano Michael Douglas; Carmela Arias y Díaz de Rábago, condesa de Fenosa y presidenta de la Fundación Pedro Barrié de la Maza; así como, el antiguo presidente del Comité Olímpico Internacional, Juan Antonio Samaranch.

En el año 2004, también peregrinaron a Santiago; Javier Irureta, ex-futbolista, ex-entrenador del Deportivo de La Coruña y en la actualidad entrenador de fútbol; el empresario gallego propietario de Inditex, Amancio Ortega; la hija del anterior Presidente de los EEUU, George. W. Bush, etc...

Los periodistas, a veces también ejercieron de buenos prescriptores, en ocasiones su participación en diferentes congresos y simposios organizados con motivo del Xacobeo, sus visitas a Santiago como auténticos peregrinos contribuyeron a que fuesen noticia. Esto hace que se hayan podido ver a lo largo de los diferentes Años Santos a reporteros convertidos en caminantes, como es el caso del cronista de The New York Times David Duffy.

Es importante mencionar la labor de prescriptor realizada por el humorista y presentador de televisión alemán Hape Kerkeling donde a través de su libro "Bueno, me largo", publicado en 2006, describe su peregrinación a Compostela. Tras recorrer casi 800 kilómetros durante seis semanas de la ruta francesa en el 
año 2001, decide escribir sus vivencias a lo largo de un viaje que dice haberle cambiado la vida. Este libro acaparó importante ventas en diferentes países convirtiéndose en un betseller incluso fuera de Alemania.

En 2008, la presencia del astrofísico británico Stephen Hawking en Santiago para recibir el premio Fonseca por sus prestigiosos descubrimientos se convertía en noticia que daba la vuelta al mundo, gracias a que aprovechaba su estancia en la ciudad para realizar un pequeño tramo del Camino de Santiago y visitar la catedral. Este aspecto generaba un reclamo para que la ruta de peregrinación volviese a estar en boca de todos.

En este sentido todas las personas que han desarrollado su labor de prescriptores, han contribuido a recomendar el producto o el evento en aras de mejorar la imagen del mismo a través de su vinculación directa o indirecta con el mismo.

\section{CONCLUSIONES}

La celebración de eventos suele ser importante para las ciudades, regiones o países, ya que además de incentivar el desarrollo socioeconómico, contribuye a la promoción del destino y creación de una determinada imagen que acabará por posicionarlo en la mente del consumidor turístico.

Así durante los últimos años, la organización de eventos se ha revelado como una de las principales estrategias de desarrollo de las ciudades al impulsar diferentes actividades, configurar atractivos turísticos, e incidir en la imagen del destino. Por eso la importancia y seriedad del tema ha generado y genera inquietudes para los gestores y promotores turísticos. 
En este sentido los orígenes del evento Xacobeo se remontan al año 1991. La idea era crear un acontecimiento alrededor de los Años Santos, pero desde una perspectiva más amplia, con la finalidad de dinamizar socioeconómica y culturalmente a Galicia.

De este modo la celebración de los tres Xacobeos 93, 99 y 04, ha influido en la imagen y posicionamiento que en la actualidad presenta Galicia como destino turístico.

No hay que obviar que en todo este proceso la comunicación representa un elemento importante como medio de transmisión de información, lo que significa que hay que prestar especial cuidado a la hora de seleccionar las estrategias y herramientas de comunicación a utilizar, puesto que de ello podría depender en cierta medida el éxito del evento, sobre todo en un primer momento.

Para el análisis de las herramientas de comunicación empleadas por este evento a lo largo del Xacobeo 93, 99 y 04, se ha recurrido a las fuentes secundarias. Dicha información ha permitido conocer las estrategias de comunicación empleadas, así como las acciones realizadas por los organismos encargados de la promoción y difusión a lo largo de los tres eventos en las principales Comunidades y países emisores de peregrinos y visitantes de día/turistas a la Comunidad.

Este año 2010 volvemos a asistir a la celebración de un nuevo Xacobeo y para ello, es importante que el nuevo ejecutivo planifique cuidadosamente la comunicación y seleccione adecuadamente las herramientas para lograr que el evento llegue a todo el mundo y se convierta en un acontecimiento que reporte importante beneficios para Galicia como comunidad. 
Los resultados acerca de la eficacia de las herramientas de comunicación empleadas a lo largo de este nuevo acontecimiento, sólo se podrán analizar una vez finalizado el mismo, por el momento sólo podemos decir que Galicia debe aprovechar al máximo este evento.

\section{BIBLIOGRAFÍA}

AGUIRRE, M.S. (Coord.) (2000): Marketing en sectores específicos. Pirámide. Madrid.

ALÉN, M.E., FRAIZ, J.A., y MAZAIRA, A. (2007): "Presión de tempo e contido informativo das promocións de vendas". Revista Galega de Economía, vol. $16, n^{\circ} 1$, pp. 95-110.

ALTÉS, C. (1993): Marketing y turismo. Introducción al marketing de empresas y destinos turísticos. Síntesis. Madrid.

ASCANIO, A. (1991): "Turismo como sistema de servicios: soportes físicos y estrategias". Papers de Turisme, $n^{\circ}$ 6, pp. 35-50.

ASHWORTH, G.J. (1991): "Products places promotion: destination images in the analysis of the tourism industry" en The Tourism industry: an international analysis. Sinclair, M.T y Stabler, M. J. Eds., pp. 121-142. Cab International, U.K.

BELLO, L.; VÁZQUEZ, R. y TRESPALACIOS, J.A. (1996): Investigación de mercados y estrategia de marketing. Civitas. Madrid.

BIGNÉ, E., FONT, X., y ANDREU, L. (2000) : Marketing de destinos turísticos. Análisis y estrategias de desarrollo. ESIC. Madrid.

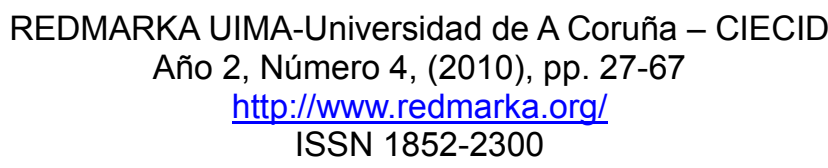


BIGNÉ, E. (2003): Promoción comercial, ESIC, Madrid.

BROACKES, J. (2009), “David Hume”, en HONDERICH, T., Los filósofos, Tecnos, Madrid

BUHALIS, D. (2000): "Marketing the competitive destination of the future". Tourism Management, $\mathrm{n}^{\circ} 21$, pp. 97-116.

COLECTIVO DE AUTORES (2003): Enciclopedia práctica profesional de turismo, hoteles y restaurantes. Océano, Barcelona.

DÍEZ, E.C. et al. (2002): Marketing, investigación, investigación comercial. Pirámide. Madrid.

ELIZAGARATE, V. (2003): Marketing de ciudades. Pirámide. Madrid.

GO, F. (1992): "El paradigma de los nuevos productos turísticos y las ventajas competitivas". Revista Valenciana d’Estudis Autonòmics, n 13, pp.75102.

GOODALL, B. (1990a): "The dynamics of tourism place marketing". Marketing tourism places. Ashworth, G. y Goodall, B. Eds., pp. 259-279. Routledge, London.

GOODALL, B. (1990b): "How tourists choose their holidays: an analytical Framework" en B. Goodall y G. Ashworth (eds): Marketing in the Tourism Industry: The Promotion of Destination Regions", Routledge, London, pp. 1-17.

HEATH, E., y WALL, G. (1992): Marketing tourism destinations. A strategic planning approach. John Wiley \& Sons, USA.

KOTLER, P. (1989): Principles of marketing. Prentice-Hall, Englewood Cliffs, Nueva Jersey.

LOIS, R.C. y SANTOS X.M., (1997): "Galicia”. La actividad turística española en 1996. Asociación Española de Expertos Científicos en Turismo (AECIT). Madrid. 
MARTíN, E. (1980): La Gestión Publicitaria, Pirámide, Madrid.

MARTÍNEZ, V.A. (2004), “Comunicación por Acción: Patrocinio y Mecenazgo", en BEL, I. (Coord), Comunicar para crear valor. La dirección de comunicación en las organizaciones, EUNSA, Pamplona MARTÍNEZ, V.A., JUANATEY, O., y BLÁZQUEZ, F. (2004): "Efectos de la corrupción en la imagen percibida de las empresas", Revista de Estudios de Comunicación ZER, Bilbao, pp. 45-66.

MARTÍNEZ, V.A., JUANATEY, O., OROSA, J., y RODRÍGUEZ, L. (2004): "Estrategias de comunicación en la gestión de la responsabilidad social de la empresa", II Encuentro IberoAmericano sobre Estrategias de Comunicación, Sevilla, 16 de septiembre de 2004.

MASSONI, S. (2007), Estrategias. Los desafíos de la comunicación en un mundo fluido, HomoSapiens, Rosario (Argentina).

MAURE, G. (2007): "Definiciones y tendencias del turismo de eventos", Contribuciones a la economía, n 82, julio 2007.

MIDDLETON, V. (1994): Marketing in travel and tourism. Butterworth Heinemann, Oxford.

MILIO BALANZÁ, I (2004): Diseño y Comercialización de Productos Turísticos Locales y Regionales, Thomson-Paraninfo, Madrid PÉREZ, R.A. (2001), Estrategias de Comunicación, Ariel, Barcelona REINARES, P. y CALVO, S. (1999): Gestión de la comunicación comercial. McGraw-Hill. Madrid.

REY, M., et al. (2004): Fundamentos de Marketing Turístico. Síntesis. Madrid. 
RODRÍGUEZ, I.A., DE LA BALLINA, J. y SANTOS, L. (1997): Comunicación comercial: conceptos y aplicaciones. Civitas. Madrid.

ROYO, M. (2002): Comunicación publicitaria: un enfoque integrado y de dirección. Minerva Ediciones. Madrid.

RUFÍN, M. (2002): Marketing (conceptos, instrumentos y estrategias). UNED. Madrid.

SERRA, F.M. (2009), "Cómo dirigir en lo fluido: Dinámica de Sistemas", en PÉREZ, R.A. y MASSONI, S., Hacia una Teoría General Estratégica, Ariel, Barcelona

SLEIGHT, S. (1992): Patrocinadores. Un nuevo y eficaz sistema de marketing. McGraw- Hill. Madrid.

VALLS, J.F. (1992): La Imagen de marca de los países. McGraw-Hill. Madrid.

WOOLHOUSE, R. (2009), “Locke”, en HONDERICH, T., Los filósofos, Tecnos, Madrid

XUNTA DE GALICIA (1994): Xacobeo 93. Santiago de Compostela.

ZEITHMAL, V.A. (1988): "Consumer perceptions of price and value: A mensend model and synthesis of evidence", Journal of Marketing, vol. 52, (julio), pp. 2-22.

ZEITHMAL, V.A., y BITNER, M.J (2000): Marketing de servicios. McGraw-Hill. $2^{a}$ edición. México.

\section{WEBS UTILIZADAS}

REDMARKA UIMA-Universidad de A Coruña - CIECID

Año 2, Número 4, (2010), pp. 27-67

http://www.redmarka.org/

ISSN 1852-2300 
http://www.caminofriends.com

http://www.santiagoturismo.com

http://www.spain.info

http://www.turgalicia.es

http://www.xacobeo.es

\section{Para citar este artículo:}

Rodríguez Fernández, Magdalena (29-04-2010). APLICACIÓN DE LAS HERRAMIENTAS DE COMUNICACIÓN A UN EVENTO TURÍSTICO: EL CASO XACOBEO.

REDMARKA - CIECID - Unidad de Investigación en Marketing Aplicado-Universidad de A Coruña, Número 4, V1, pp.27-67

ISSN 1852-2300

URL del Documento : http://www.cienciared.com.ar/ra/doc.php?n=1256

URL de la Revista : http://www.cienciared.com.ar/ra/revista.php?wid=39 